\title{
The Knowledge Dimension of Production Transfer
}

\author{
Jens O. Riis ${ }^{1}$, Brian Vejrum Waehrens ${ }^{1}$, and Erik Skov Madsen ${ }^{2}$ \\ ${ }^{1}$ Center for Industrial Production, Aalborg University, Fibigerstraede 16, DK-9220 Aalborg, \\ ${ }^{2}$ Department of Industrial and Civil Engineering, University of Southern Denmark, \\ Niels Bohrs Alle 1, DK-5230 Odense, Denmark \\ riseproduction.aau. dk
}

\begin{abstract}
Empirical studies in three industrial companies have revealed that even companies with many years of experience in production transfer tend to focus attention on planning the physical transfer and on the explicit knowledge associated with normal production. They are uncertain about capturing, transferring and developing tacit knowledge. Supported by studies of the literature it is concluded that there is a need for a more systematic approach to knowledge transfer and development to provide an accelerated ramp-up after the physical transfer. A framework will be structured around a generic set of phases of the transfer process and a distinction between the sending and the receiving organizational unit. A method for capturing the tacit knowledge embedded in a production job has been developed and tested. The framework and the method will provide a basis for preparing a master plan for knowledge transfer and development.
\end{abstract}

Keywords: Production transfer; Tacit and explicit knowledge; Absorptive capacity.

\section{Introduction}

Increasingly, industrial enterprises outsource and offshore production to gain from low costs and/or to be close to expanding markets. This implies transferring production facilities and knowledge to another country. Much attention has been given to the choice of new location, design of plant-layout and transfer of physical production facilities, whereas the knowledge transfer and development at the new site remains largely unexplored [1]. In many instances this has become a critical issue, as much of the knowledge determining current operations is tacit and difficult to capture.

This paper will take outset in the thesis that future competitive advantage will not be based on a simple relocation or outsourcing of manufacturing processes to low cost regions; rather it is expected to be found in the company's ability to identify and disseminate best practice, knowledge, market information and capabilities, which are rooted in manufacturing networks [2], [3]. The speed of successful transfer will be important.

\subsection{Theoretical Background}

Ferdows [1] has developed a valuable classification into four archetypical situations illustrated by selected firms and their way of developing explicit and tacit knowledge 
component. This study along with several studies, however, reports at a general level about the successful relocation of manufacturing activities, but does so without providing a deeper understanding of the tacit knowledge in operation on the shop floor. Few exceptions to this can be found, one being a treatment of the tacit dimension of shop floor activities during different phases of factory maturity [4], and another a discussion of knowledge transfer within a multi-national enterprise [5].

In a comprehensive empirical investigation of knowledge transfer, Szulanski [6] studied eight companies and investigated how best practice was transferred, and he found that the major barriers to internal knowledge transfer were related to internal stickiness, factors like lack of absorptive capacity [7], casual ambiguity and arduousness of the relationship between the source and the recipient.

Knowledge is essentially related to human action [8]. Individuals create knowledge, but organizations create a context for individuals to create and utilize knowledge. The knowledge acquired from a sending plant can be explicit or tacit, and can be grafted to take root into the receiving plant via socialization, internalization, and by combining different types of explicit knowledge to create new knowledge that is useful within the receiving context. The notion of collective knowledge represents the mutual interplay between organizational members when they together perform a task. The Kolb learning circle suggests focus on reflection and experimentation as important elements of transfer of especially tacit knowledge [9].

\subsection{Purpose and Outline of the Paper}

There is a need for developing a comprehensive framework for dealing with the knowledge dimension of production transfer, and for addressing the issue of capturing, transferring and developing the tacit knowledge associated with operations at the shop floor level, being individual as well as collective in nature.

The paper will address this issue by first presenting a framework for a systematic and comprehensive attention to the knowledge dimension of production transfer. Then a method for identifying tacit knowledge at the sending organizational unit will be presented and discussed. And finally, activities will be proposed for preparing a master plan for knowledge transfer and development.

\subsection{Empirical Background}

The paper will rest on empirical studies over a period of two years in three large Danish manufacturing companies. All companies have most of their activities outside Denmark and form a wide technological range from manual assembly of industrial components, over semi-automatic production to a fully automated and high-tech electronics production line. In addition, the developed methods have successfully been applied in three minor cases.

The empirical studies have included a survey of documents on the shop floor to uncover the presence of explicit knowledge like work instruction, drawings, maintenance procedures, spare part list etc. Furthermore, a total of 81 semi-structured interviews were carried out at all levels in the organizations in Denmark, Eastern Europe and in Latin America.

For a more detailed exposition of the case studies, as well as the theoretical background, analyses and applied means see Madsen [10]. 


\section{A Framework for the Transfer Process}

On the basis of the case studies and pertinent literature we have developed a framework for addressing the knowledge dimension of transfer, cf. fig. 1.

Context Complexity and uncertainty
Green field or Brown field
\begin{tabular}{|c|c|c|c|c|c|c|c|}
\hline $\begin{array}{c}1 . \\
\text { Initiating } \\
\text { decisions }\end{array}$ & $\begin{array}{c}2 . \\
\text { Preparation }\end{array}$ & $\begin{array}{c}\text { Initial training } \\
\text { and } \\
\text { education }\end{array}$ & $\begin{array}{c}4 . \\
\text { Transfer }\end{array}$ & $\begin{array}{c}5 . \\
\text { Test } \\
\text { production }\end{array}$ & $\begin{array}{c}6 . \\
\text { Production } \\
\text { with } \\
\text { moderate } \\
\text { output }\end{array}$ & $\begin{array}{c}7 . \\
\text { Improvement } \\
\text { of production }\end{array}$ & $\begin{array}{c}8 . \\
\text { Production } \\
\text { development, } \\
\text { Cl and } \\
\text { innovation }\end{array}$ \\
\hline
\end{tabular}

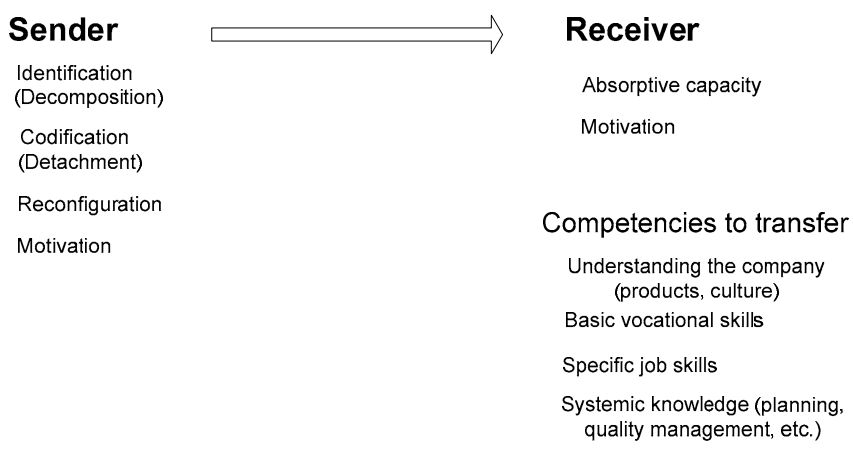

Fig. 1. A framework for planning knowledge transfer and development in production transfer

\subsection{A Phased Process}

Based on [11] we have extended the four phases proposed by Szulanski [12] to include a training and education phase prior to the physical transfer and additional phases after the transfer to indicate a step-wise development of operation competencies in the receiving unit, cf. fig. 1. Each phase has its distinct set of tasks, the nature and content of which will depend on the actual situation at hand.

Figure 1 shows four different types of competencies. In case of a green field transfer much effort need be devoted to provide an understanding of the corporate culture, and also to introduce operators to the management systems and modes of operations.

Following the Shannon \& Weaver model of a transmitter and a receiver of communication [13], two key actors have been identified, namely a sending and a receiving organizational unit.

\subsection{The Sending Organizational Unit}

Four issues of knowledge transfer are related to the sending unit.

Identification of knowledge in the sending unit. Drawing on systems theory, this involves decomposing the overall task to manageable elements, for example to define 
the knowledge associated with specific production jobs. A substantial part of operations knowledge is associated with the interplay of several individuals and organizational units, for example in carrying out production planning and quality management. This kind of knowledge cannot easily be decomposed into clearly defined elements.

Codification of knowledge. As pointed out for example in [1], much of the essential production knowledge is not explicit, but tacit. This means that they are only visible when enacted. A special effort, thus, is needed to capture tacit knowledge, to be discussed in a subsequent section.

Reconfiguration. As evidenced in the case studies, a production unit to be transferred is likely to be subjected to a technological update or reconfiguration in an effort to ensure a successful transfer.

Motivation. If a transfer of a production unit implies that operators are to be let off, it may be hard to motivate them to assist in transferring explicit and tacit knowledge to the receiving unit.

\subsection{The Receiving Organizational Unit}

The empirical studies indicate that in particular two factors should be considered.

Absorptive Capacity. Cohen \& Levinthal [7] have made an extensive research of 1719 business units and their ability to recognize the value of new, external information, assimilate it and use it as new knowledge. They call it Absorptive Capacity and suggest that this is largely a function of the company's capacity for absorbing something new related to individual, group, organizational and environmental level.

Motivation. The empirical studies indicate that it is important for a speedy ramp-up in the receiving unit that operators are motivated. Some of the means include a step-wise development of competencies, for example by following the Dreyfus \& Dreyfus [14] steps from novice via advanced beginner and competent operator to expert. Another means is to involve operators in improvement initiatives in the new location. In one of the case studies, a Lean program was initiated shortly after the physical transfer. Not only did this help newly appointed operators to systematically be introduced to their jobs, but they became also very much engaged in suggesting improvements, which resulted in a markedly increase in the sense of ownership.

\section{Identifying Tacit Knowledge}

Observations of practice indicate that managers find it difficult to capture the tacit knowledge embedded in many production jobs. As a result, they tend to focus only on the explicit knowledge part and to leave it to operators themselves to transfer tacit knowledge through application of unstructured peer-to-peer training.

Tacit knowledge may be held by an individual in the company and by a group of persons who are capable of solving complex problems by working together in an informal way using their intuition and mutual experience.

By its very nature, tacit knowledge is difficult to identify. To this end we have developed a method that may help operators and technicians identify significant tacit 
elements of their knowledge, as a pre-requisite for a systematic transfer [15]. It rests on a model illustrating how different levels of uncertainty and complexity make up four distinctive work situations, which require different competencies, means and institutional support. They also rely on different representations of knowledge, cf. fig.2.

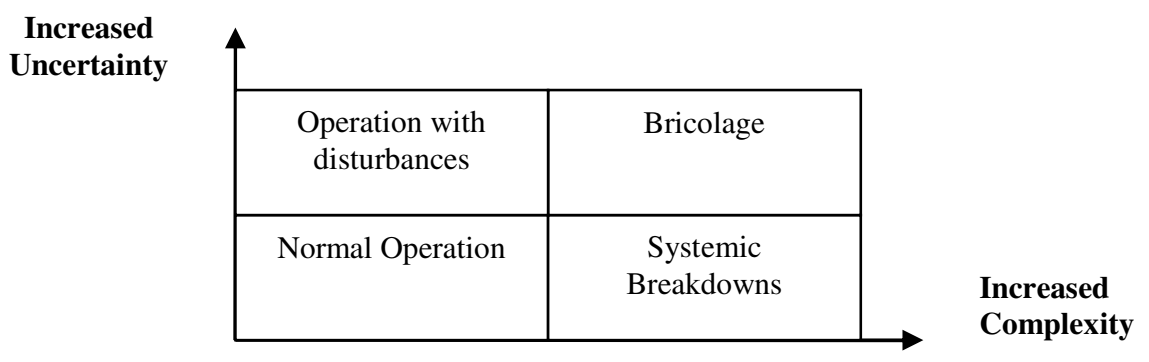

Fig. 2. Dimensions of task situations on the shop floor

A less complex task is expected to be carried out by a single operator whereas a more complex task usually requires the involvement of several operators and specialists with different kinds of knowledge and experience. The uncertainty axis may similarly be divided into a less uncertain and a more uncertain task situation; the former characterized by a high degree of predictability and regularity, and the latter dominated by a lack of knowledge of what incidents may happen and when.

Normal operation constitutes a situation where everything functions as planned and prescribed. The less-experienced operators used drawings, SOPs, maintenance instruction, quality instruction and manuals, all of which also served as a vehicle for discussions between the experienced operator and the new operator.

Operation with disturbances denotes that operators at the individual level experience incidents that occur randomly and call for an extra effort and supplementary knowledge. It could be a spot of rust or a burr on the component to be assembled, which the operator had to let pass, remove or decide if he had to scrap the component. It could also be unplanned stops of a machine due to wear of tooling, stops of a robot or disturbances in connection to sophisticated and automated equipment. The knowhow about how to handle these disturbances was possessed by experienced individuals in the sending context.

Systemic breakdowns. In this situation incidents do not readily point to a solution; rather they require a great diagnostic effort, mainly due to a complex set of interactions between technologies and people. In our case studies, the manufacturing equipment combined a large number of different sophisticated technologies, e.g. robots, PLC controls, computer control, pneumatics, hydraulics, electronics, mechanics, CNC tooling machinery with a high degree of complexity. Unskilled operators found it difficult to cope with such situations, and the complexity called for a diverse set of skills, know-how, and a social dimension embedded in the informal task environment of the work place. 
Bricolage. Levi-Strauss [16] introduces the term bricolage to denote the social and intuitive dimension where employees use available means when searching for mundane solutions to complex problems. Incidents of this situation are dominated by a high degree of complexity and call for much know-how and experience of each individual within the group. Because of the mutual interplay of different technologies, skills and organizational units, this situation requires a combined effort of several persons and different departments in making creative and resourceful use of whatever materials are at hand.

\subsection{The Model in Use}

The model has been tested as a tool for identification and structuring of knowledge when planning a knowledge transfer process.

In one of the case studies, management used the model when reflecting on the whole transfer process. "Normal Operation" was discussed in relation to documentation and SOPs and it was shown that they were able to enlarge the "Normal Operation". Most of the tasks related to "Operation with disturbances" and "Systemic Breakdows" were solved by set-up fitters and technicians. However, in cases of "Bricolage" processes and methods were challenged and called for much attention to be able to capture, transfer and develop knowledge, and also to develop a culture at the group level in the receiving unit.

The model was also found useful in another case study where knowledge was to be shared within a group of 15 to 18 planners who were located in groups of two to three persons at different offices in a factory. The model was used by the planners to systemize an internal training process. Tasks of "Normal operation" and "Operation with disturbances" were identified and planned to be trained in such a way that all planners could carry out these tasks. "Systemic breakdowns" should only be solved by a group of five super users. "Bricolage" was identified to include a number of uncertainties that would also call for cooperation with internal and external partners. Therefore "Bricolage" tasks were planned to be managed by two expert planners.

In general we suggest that for a given transfer job 5-10 non-normal situations be defined. Then experienced operators and set-up fitters should discuss how they usually handle these situation, thereby unveiling tacit knowledge. In this way a repository for transfer of tacit knowledge may be established.

\section{Preparing a Master Plan for Knowledge Transfer and Development}

Outset is taken in the framework model in figure 1 to prepare a master plan for knowledge transfer. It may include the following steps:

Define the overall knowledge transfer and development tasks in a specific production transfer situation. This will include the strategic role and tactical decisions (scope, time frame, what should be transferred and what should not, management approach, etc). 
Analysis of jobs to be transferred and the nature of knowledge. As discussed above, it is difficult to identify the tacit knowledge to be transferred. The proposed method (section 3) may help capture both individual and collective tacit knowledge. In addition, analysis of the sending and the receiving organizational unit will provide an idea of the competencies to be developed and the motivation and absorptive capacity in the receiving unit.

Identifying possible means for competence development. Several means exist for training operators on the basis of explicit knowledge, such as instruction sheets, training sessions and exercises. On the other hand, the industrial companies involved in our empirical studies had only a narrow repertoire of means for systematic dealing with tacit knowledge.

The learning circle developed by Kolb [9] provides a background for choosing appropriate means for addressing tacit knowledge transfer and development; for example

Reflection. A common understanding of practice may surface by involving different groups of employees in diagnosing a problem, e.g. around a white board.

Active experimentation. Proposed solutions may be tested as part of an active experimentation process, for example by using games and simulation. The Japanese production philosophy includes Continuous Improvement as a key element, and this has also been adopted in the Lean Thinking.

Preparing a master plan for knowledge transfer and development. On the basis of the above mentioned steps, we shall propose that for each phase of the transfer process to plan what action should be taken for both the sending and the receiving unit. Also the Dreyfus \& Dreyfus model of pedagogical steps in competence development may be used to address the question of who (operators, technicians, foremen, etc.), what (which competencies), when, and how [14].

\section{Discussion and Conclusion}

The empirical studies have revealed that even companies with many years of experience in production transfer tend to focus attention on planning the physical transfer and on the explicit knowledge associated with normal production and are uncertain about capturing, transferring and developing tacit knowledge. These observations initiated development of a more systematic analysis and planning resulting in the proposed framework and method, e.g. figure 1 and 2. Also additional case studies offered opportunities for testing part of the framework.

At the moment, one of the case companies has decided to use the developed framework and method to initiate a concerted and systematic effort to gather and further develop and use the overall experience in the company, recognizing that knowledge transfer and development will be a key competitive factor in future distributed production.

The developed framework and methods will enable an accelerated transfer of knowledge by guiding managers to systematically address key issues. This will provide a more solid background for trying out new training means, especially those aimed at stimulating development of tacit knowledge, individual as well as collective. 
Training means that have proven successful in other industries can also beneficially be applied to industrial operations, for example flight simulator. The proposed framework, in this way, will help managers to address an important issue that have been neglected so far.

\section{References}

1. Ferdows, K.: Transfer of Changing Production Know-How. Production and Operations Management 15(1) (Spring 2006)

2. Grant, R.M.: Prospering in Dynamically-competitive environments: Organizational Capability as Knowledge Integration. Organization Science 17(4), 375-387 (1996)

3. Quinn, J.B.: Strategic outsourcing: Leveraging knowledge capabilities. Sloan Management Review 40(4), 9-21 (1999)

4. Patriotta, G.: Organizational Knowledge in the Making. Oxford University Press, Oxford (2003)

5. Dyer, J., Nobeoka, K.: Creating and Managing a High Performance Knowledge-sharing Network: The Toyota Case. Strategic Management Journal 21, 345-367 (2000)

6. Szulanski, G.: Exploring Internal Stickiness: Impediments to the transfer of best practice within the firm. Strategic Management Journal 17 (1996) (Winter Special Issue)

7. Cohen, W., Levinthal, D.: Absorptive capacity: A new perspective on learning and innovation. Administrative Science Quarterly 35(1), 128-152 (1990)

8. Nonaka, I., Takeuchi, H.: The Knowledge-Creating Company. Oxford University Press, New York (1995)

9. Kolb, D.A.: Experimental learning. Prentice-Hall International, London (1984)

10. Madsen, E.S.: Knowledge transfer in global production, $\mathrm{PhD}$ thesis, Aalborg University (2009)

11. Maritan, C.A., Brush, T.H.: Heterogeneity and transferring proactice: implementing flow manufacturing in multiple plants. Strategic Management Journal 24, 945-959 (2003)

12. Szulanski, G.: The process of knowledge transfer: A diachronic analysis of stickiness. Organizational Behavior and Human Decision Processes 82(3), 9-27 (2000)

13. Shannon, C.E., Weaver, W.: The Mathematical theory of communication. The University of Illinois Press, Chicago (1949)

14. Dreyfus, H.L., Dreyfus, S.E.: Mind over machine, The Power of Human Intuition and Expertise in the Era of the Computer. Free Press, New York (1986)

15. Madsen, E.S., Riis, J.O., Waehrens, B.V.: The Knowledge Dimension of Manufacturing Transfers - A method for identifying hidden knowledge. Strategic Outsourcing an International Journal 1(3) (2008)

16. Levi-Strauss, C.: The Savage Mind. University of Chicago Press, Chicago (1967) 